\title{
Slow progress to reproductive rights
}

Religious fundamentalism and a lack of resources are the chief barriers to achieving sexual and reproductive rights for all by 2015, concluded the 2004 International Conference on Population and Development (ICPD)

Seven hundred participants from 109 countries gathered in London on Sept. 2 to review progress toward achieving the Cairo Consensus, which was ratified by 179 nations at the 1994 ICPD.

Participants heard that access to contraception and the enrolment of girls in schools have improved globally, but that infant and maternal mortality, unwanted

을 pregnancies and unsafe abortions

if remain dangerously high. Every

$\because$ year about 529000 women die from complications of pregnancy and childbirth, and 10\% of pregnancies (about 19 million) end in $\because$ unsafe abortions, resulting in 70

$\stackrel{0}{\circ} 000$ maternal deaths. The ICPD report card on 133 countries (www.countdown2015.org) also reveals 123 million couples have an urgent need for contraception.

The Bush administration's "abstinence only" policy, which precludes funding groups that provide information about abortion, as well as the conservative reaction by the Vatican and some Islamic countries were excoriated at the conference for undermining the Cairo Consensus.

Inadequate funding also hinders progress. Contributions from developed countries reached about US\$2.3 billion in 2003; the conference target was US\$6.1 billion by 2005 .

"Cairo's promises have not moved from the paper they were written on," lamented the Director General of the International Planned Parenthood Federation. "[R]ich countries need to understand the importance of the Cairo goals to peace and security;

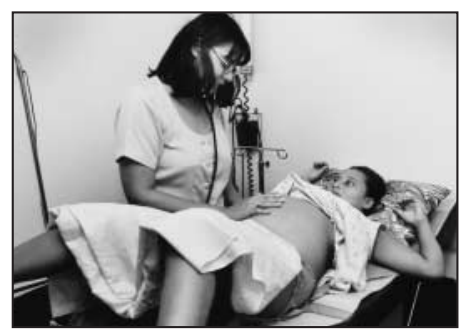

Teen pregnancy: 123 million couples want contraception.

all countries must commit the funding," said Steven Sinding.

Katherine McDonald, president of Action Canada for Population and Development, said that advocates of the Cairo consensus have been overly distracted by their efforts to isolate and shame US and conservative backlash and must reinvest in a commitment to human rights.

"In-depth policy analyses of sexual, reproductive, and abortion rights are lacking," she said. - Focalyn Clark, London, UK 